\title{
Chave para as famílias e gêneros da Mecoptera (Insecta) da América, do sul dos Estados Unidos
}

\author{
Norman D. Penny (") \\ George W. Byers ("*)
}

\begin{abstract}
Resumo
Uma chave é apresentada para identificar as famílias e gêneros da ordem Mecoptera na regiâo da América, sul dos Estados Unidos.

\section{Chave}

1.A. Cada tarso com uma garra grande, raptórial, a qual, junto com o quinto tarsomero dobra contra o quarto tarsomero. Pernas compridas, assemelhando aquelas de um tipulídeo. Nas antenas, os segmentos do flagelo bem mais compridos que largos. Larvas eruciformes, com quatro projeções carnosas em cada segmento abdominal, e com 8 pares de pernas abdominais; olhos com um agrupamento de sete omatídios em forma de anel ....... BITTACIDAE .....4

B. Cada tarso com duas garras, não modificadas para uso raptórial. Nas antenas, os segmentos do flagelo pouco mais comprido que largos ........... 2

2.A. Asas com mais de $30 \mathrm{~mm}$ de comprimento, mais compridos que na maioria dos bittacídeos, etc., largos com mais de 50 nervuras transversais. Rs com origem perto da base da asa. M bifurcada antes da metade da asa. Corpo deprimido, a forma assemelhando uma barata com rostro alongado. Estágios imaturos desconhecidos. (Uma espécie, Notiothauma reedi MacLachlan, no Chile) $\ldots \ldots \ldots \ldots$ NOTIOTHAUMIDAE

B. Asas alongadas e estreitas, menos de $25 \mathrm{~mm}$ de comprimento com inervação normal ou reduzida (menos de 30 nervuras transversais). Rs com origem após o primeiro $1 / 3$ basal da asa; $M$ bifurcada perto do meio da asa. Corpo não deprimido $\ldots \ldots \ldots \ldots \ldots \ldots \ldots$

3.A. Asas pequenas $(5,5$ até $8,5 \mathrm{~mm})$ com nervação reduzida (menos de 15 nervuras transversais). $\mathrm{Na}$ asa anterior, $\mathrm{Sc}$ termina na $R$; Rs com 3 ramais. Rostro menos que o tamanho dorso-ventral do olho. Larva elateriformes, vivendo em córregos onde a água corre rapidamente. (Um gênero, Nannochorista, com duas espécies, da Argentina e Chile) ........... NANNOCHORISTIDAE

B. Asas com comprimento de 10 a $15 \mathrm{mmm}$, com mais de 20 nervuras transversais. Nas asas anteriores, Sc terminando na C; Rs com 4 ramais. Larva eruciformes, vivendo no solo. (Um gênero, Panorpa, nas montanhas do planalto central do México) ........... PANORPIDAE

4.A. Olhos muito grandes, tocando-se embaixo das bases das antenas. (Seis espécies desde Panamá até Peru) ... Pazius Navás.

B. Olhos bem separados embaixo das bases das antenas ............ 5

5.A. $M_{4}$ com origem na primeira bifurcação da $M$; sem nervuras transversais pterostigmatas. Macho sem lobulos epiandriais; cercos grandes essemelhando lobulos epiandriais. (Uma espécie, Anabittacus iridipennis Kimmins. no Chile) .............. Anabittacus Kimmins.

B. Origem da $M_{4}$ na segunda bifurcação da $M$; com nervuras transversais entre $R_{1}$

(•) - Instituto Nacional de Pesquisas de Amazônia, Manaus.

$\left({ }^{\circ}\right)$ - Dept. of Entomology, University of Kansas, Lawrence, U.S.A. 
e $R_{2}+_{3}$. Macho com lóbulos epiandriais conspicuous; cercos finos ou levemente pouco expandidos .............6 6

6.A. Nervura $1 \mathrm{~A}$, na asa anterior, mais curta que, ou somente chegando ao nível da origem da $M$; nervura $M_{1}+2$ mais arqueada que $M_{3}+{ }_{4} \ldots \ldots \ldots \ldots \ldots \ldots, 7$

B. Nervura $1 \mathrm{~A}$, na asa anterior, chegando bem além da origem da $M$; nervuras $M_{1}+_{2}$ e $M_{3}+_{4}$ quase igualmente arqueadas $\ldots \ldots \ldots \ldots \ldots \ldots \ldots \ldots, \ldots$

7.A. Somente uma nervura transversal pterostigmatal ................ 8

B. Duas nervuras transversais pterostigmatais (três espécies desde México até Panamá) ....... Kalobittacus E.-P.

8.A. Aedeago simplesmente recurvado; nervura $\mathrm{Cu}_{2}$, da asa anterior, vai bem além do nível da primeira bifurcação da $\mathrm{M}$.
(Duas espécies desde Panamá até o Brasil) ......... Nannobittacus E.-P.

B. Aedeago enrolado; nervura $\mathrm{Cu}_{2}$, da asa anterior, termina antes ou ao nivel da primeira bifurcação da $\mathrm{M}$. (Uma espécie do Brasil e da Bolívia)

Issikiella Byers

9.A. Três ou quatro nervuras transversais costais após da nervura transversal humeral (h). (Duas espécies no Brasil) ................ Neobittacus E.-P.

B. Quase sempre sem nervuras transversais após h, raramente exista duas. (19 espécies desde México até Chile). ................. Bittacus Latreille

\section{SUMMARY}

A key is presented for families and genera of American Mecoptera south of the United States. 